\title{
Jill Alpes, Emergency returns by IOM from Libya and Niger
}

(2020) Brot für die Welt / medico internacional e.V. Berlín, 24 pp.

\author{
Felipe González Morales* \\ Universidad Diego Portales \\ ORCID ID 0000-0003-0446-8973 \\ felipe.gonzalez@udp.cl
}

Cita recomendada:

González Morales, F. (2021). Jill Alpes, Emergency returns by IOM from Libya and Niger. Eunomía. Revista en Cultura de la Legalidad, 21, pp. 435-440

DOI: https://doi.org/10.20318/eunomia.2021.6367

Recibido / received: 04/05/2021

El empleo de los retornos de personas en situación de movilidad es una práctica que se ha vuelto masiva en diversas regiones del mundo en los últimos años, constituyendo en la actualidad una de las medidas más comunes de la política migratoria de muchos países de destino. El Informe publicado en 2020 por Brot für die Welt (Pan Para el Mundo) y Medico International (en adelante «el informe» o «Pan Para el Mundo») aborda el tema en Libia y Níger y su impacto en el contexto subregional africano. Se trata de dos Estados en que la práctica masiva de retornos presenta serios desafíos desde el punto de vista de la protección de los derechos humanos de las personas migrantes.

Un aspecto especialmente controvertido es el de la distinción entre retornos voluntarios e involuntarios. En este sentido, la Relatoría Especial sobre derechos humanos de los migrantes de la Organización de Naciones Unidas (ONU) ha señalado que:

[E]n general, las condiciones en las que los migrantes solicitan el retorno voluntario asistido no permiten calificar el retorno de voluntario, ya que no reúnen los requisitos de una decisión plenamente informada, sin coacciones y respaldadas por la disponibilidad de suficientes alternativas válidas (Relator Especial, 2018, párr. 30).

\footnotetext{
*El autor agradece la colaboración de Julia García Martínez en la preparación de esta recensión.
} 
El abordaje conjunto que realiza el informe de los retornos desde Libia y Níger no es casual: ambos Estados se encuentran estrechamente ligados en su evolución en materia de políticas migratorias. Mientras Libia fue un Estado fuerte, servía de barrera de contención a quienes migraban en África desde el Sur hacia el Norte y Níger constituía fundamentalmente un Estado de tránsito en esa ruta. Una vez que Libia se volvió un Estado fallido, Níger se transformó en un Estado de contención. Asimismo, debido al gravísimo incremento de las violaciones a los derechos humanos de los migrantes en Libia, crecen exponencialmente los retornos, los cuales se llevan a cabo primordialmente vía Níger.

Tanto las medidas de contención migratoria como las de retornos masivos de migrantes se insertan, como señala el informe, en políticas de externalización del control de la migración. Se trata de políticas que han alcanzado una dimensión global, como lo demuestran los casos de Estados Unidos con México y Centroamérica y de Australia con Papúa-Nueva Guinea, entre diversos otros en las distintas regiones del mundo. En lo que se refiere a Libia y Níger, la externalización es llevada a cabo por la Unión Europea, a través de una serie de acuerdos, financiamiento y acciones de incidencia en la adopción de legislación y políticas internas de dichos países (Mlambo, 2020; Ferstman, 2020).

Libia era hasta hace algunos años tanto un país de destino como de tránsito para quienes trataban de emigrar a Europa utilizando la ruta del Mediterráneo Central. Sin embargo, la inestabilidad política de dicho país en la última década, sumada a la aplicación del acuerdo entre la Unión Europea y Turquía (que cerró en gran medida la ruta de los Balcanes occidentales), así como las patrullas fronterizas junto con los radares costeros que han dificultado la entrada a Europa desde Marruecos (ATTIR, 2018), han reforzado el perfil de Libia como país de tránsito. Como señala el informe, en este nuevo contexto Libia pasó a ser un foco de atención y la Organización Internacional para las Migraciones (OIM), con apoyo financiero de la Unión Europea, comenzó a emprender programas de retorno de migrantes a sus países de origen y a terceros países. Estos retornos aumentaron posteriormente en gran escala, especialmente a raíz de la difusión de imágenes de una subasta de esclavos de migrantes africanos en Libia por la CNN (Pan para el Mundo, 2020, p. 5; Kleist, 2017).

El informe apunta cómo tras dichas revelaciones los gobiernos africanos cambiaron su postura, dejando atrás la controversia que planteaba el apoyo europeo a los guardacostas libios en sus funciones de búsqueda y rescate a través de formación y recursos e infraestructura. En la $V$ Cumbre de la Unión Africana-Unión Europea los gobiernos africanos aceptaron el retorno voluntario de sus ciudadanos en Libia en el contexto de la urgencia humanitaria (Pan para el Mundo, 2020, p. 6).

La inestabilidad política y el vacío de poder en Libia han dado lugar a situaciones que incrementan las vulnerabilidades de los migrantes, muchos de los cuales han sido objeto víctimas de detención arbitraria; tortura y otros tratos crueles, inhumanos o degradantes; violencia sexual y otras formas de violencia de género (KIRBY, 2020); esclavitud y prácticas análogas a la esclavitud; devolución; desapariciones forzadas; ejecuciones; y denegación de requisitos básicos para la vida, como alimentos, medicinas y alojamiento (Committee, 2019). En algunos casos, las personas han quedado a merced de funcionarios o bandas corruptas que han recurrido a la extorsión y a las amenazas de más violencia a cambio de promesas de seguridad (Pan para el Mundo, 2020, p. 13). Teniendo en cuenta la situación en Libia, el informe en análisis describe un contexto para que los migrantes acepten los retornos y cuestiona la dificultad de sostener que estos retornos sean voluntarios. Del mismo modo, en el trabajo de campo del citado informe, las personas entrevistadas 
manifiestan que los retornos son percibidos como un control de su libertad de elección y su movilidad más que como opciones libremente aceptadas.

Con todo ello, el informe pone de relieve que estas prácticas de retornos ofrecen vías de escape a situaciones de grave desprotección de los derechos humanos, sin abordar suficientemente vulnerabilidades específicas que presentan las distintas personas ni actuar sobre las causas estructurales que son el motor de su migración, subrayando que la reintegración es posible únicamente si el retorno ha sido verdaderamente voluntario, informado, libre de coacción y con conocimiento suficiente de las alternativas (Relator Especial, 2018). Siendo así, el informe cuestiona la efectiva vigencia de los principios claves que la OIM establece para los retornos, a saber, que estos deben ser voluntarios, humanos y dignos, además de favorecer la reintegración para que tras el retorno las personas no se vean obligadas a migrar de nuevo (OIM, 2018).

Por otro lado, el informe hace referencia a las devoluciones que son efectuadas desde Libia hacia Nigeria, conocidas como Retorno Humanitario Voluntario (VHR, por sus siglas en inglés), analizando la actuación de la OIM con carácter previo a la ejecución de los retornos. Al respecto, el informe enfatiza que, pese a operar con protocolos y normas preestablecidas para la evaluación de las diversas situaciones que presentan los migrantes, unos y otras solo son aplicadas de modo superficial, sin atender a situaciones individualizadas tras una evaluación detallada y eficaz de los riesgos que puedan presentar.

De acuerdo con el informe, tras la llegada a Nigeria de los migrantes retornados, les es ofrecida asistencia que se circunscribe a sus necesidades más acuciantes, tales como la atención humanitaria primaria para los que presentan evidentes riesgos al momento de la llegada. No se ofrece un seguimiento en la posterior fase de reintegración ni se aplica una respuesta individualizada para determinar la pertenencia a colectivos con necesidades particulares, tales como niños y niñas, víctimas de trata, personas con discapacidad, migrantes adultos mayores y personas con necesidades médicas. El informe denuncia explícitamente la falta de recursos con los que la OIM-Nigeria cuenta para la ejecución de estos programas y las dificultades que se les plantean a los retornados para acceder a los proyectos de la OIM, debido a la falta de recursos básicos tales como medios de transporte 0 recursos telemáticos (Pan para el Mundo, 2020, p.16).

Por todo lo expuesto, añade el informe, los retornados siguen enfrentándose a necesidades de protección que no son suficientemente abordadas, haciendo mención especial a las deficiencias en el acceso sanitario y en las tasas de escolaridad, así como a la ausencia de seguridad social para quienes retornan. De igual modo, incide negativamente el que los planes de asistencia para la reintegración estén enfocados desde la perspectiva de prestar ayuda de modo puntual y de incentivar el emprendimiento individual, sin vínculos con planes nacionales y regionales de desarrollo o con estrategias de desarrollo económico de ámbito local, por lo que la movilidad social sigue dependiendo en gran medida de las posibilidades de movilidad geográfica.

En lo que concierne a Níger, la situación migratoria es especialmente compleja, ya que se cruza una política de retornos hacia y desde ese país con sus políticas de contención de la movilidad dirigida hacia el Norte de África y eventualmente a Europa. Dada la inestabilidad política en Libia -que solía servir de «muro» de contención-, la Unión Europea ha promovido y financiado dichas políticas en Níger (que era hasta hace unos años un país de tránsito), procurando impedir el paso de personas que no sean residentes hacia la mitad norte del país. La legislación 
más relevante al respecto fue adoptada por Níger en 2015, e incluye numerosas medidas de criminalización de la migración y de limitación de la ayuda humanitaria por la sociedad civil a quienes migran, conduciendo a que la movilidad se lleve a cabo por rutas más peligrosas (Relator Especial, 2019).

Tal como se describe en el informe, el volumen de retornos hacia y desde Níger se ha incrementado exponencialmente en los últimos años. La situación de las personas retornadas vía Níger vuelve particularmente acuciante la cuestión del carácter voluntario o no de los retornos. Según se señala en el informe en análisis y se constata asimismo en el informe de la visita oficial del Relator Especial sobre migrantes a Níger (Relator Especial, 2019), muchas de esas personas firman aceptando ser enviadas desde Níger a sus respectivos países luego de haber vivido dramáticas experiencias en el Mediterráneo, en Libia o en otros países (por ejemplo, siendo abandonadas por Argelia en el desierto, debiendo caminar 12 kilómetros hasta Níger) y en ausencia de condiciones de apoyo social en Níger que les permitan optar por una alternativa. Tampoco existen mecanismos de acceso a la justicia para que las personas migrantes formulen reclamos. En rigor, se trata en muchos casos de personas que por ser nacionales del Economic Community of West African States (ECOWAS) pueden permanecer durante seis meses en Níger. Sin embargo, la mayoría no lo hace, debido a que Níger carece de medidas de apoyo y no les brinda la posibilidad de regularizar su situación migratoria. Aunque se trata de un Estado extremadamente pobre, que en varias oportunidades ha ocupado el último lugar en el índice de Desarrollo Humano del Programa de las Naciones Unidas para el Desarrollo (PNUD), un volumen abrumador de los fondos que el país recibe desde el extranjero para la implementación de sus medidas migratorias va dirigido a la adopción de medidas de seguridad en desmedro de las de carácter social. Muchas de las personas entrevistadas manifiestan que una vez que sean retornadas a sus países pasarán un tiempo en ellos e intentarán nuevamente emprender el camino de la migración.

El informe da cuenta además de la situación de las personas deportadas desde Argelia a Níger que no son nacionales de Estados africanos, como, por ejemplo, ciudadanos de Pakistán, Siria, Yemen y otros países asiáticos. En estos casos, la OIM las transfiere al Alto Comisionado de las Naciones Unidas para los Refugiados (ACNUR), que ha establecido Campos de Refugiados, en los cuales algunas personas y familias llevan años.

La situación en Níger, según se describe en el informe (Pan para el Mundo, 2020, pp. 14-15), da cuenta de la dualidad de papeles que desempeña allí la OIM y que ha sido fuente de críticas. Por una parte, en la frontera con Argelia, la OIM presta ayuda humanitaria sin condiciones a quienes han sido abandonados en el desierto, transportándolos hasta la ciudad más cercana y proporcionándoles agua y comida. Por otra, para continuar prestándoles ayuda, la OIM requiere que la persona acepte un «retorno voluntario» a su país de origen, que es practicado por esa misma institución. Quienes no aceptan firmar su retorno, por lo mismo, quedan entregados a su propia suerte, debido a la carencia de otras formas de apoyo institucional, ya sea por el Estado u organizaciones de la sociedad civil, estas últimas limitadas en sus funciones por las normas adoptadas en 2015.

Una vez de regreso en sus países de origen -describe el informe- las personas retornadas se ven enfrentadas a graves problemas de reintegración de orden económico y social. Como señala el informe, al respecto se debería «considerar no solamente las necesidades individuales de los retornados, sino la de los miembros de sus familias en los países de origen que pueden depender de la migración y las remesas para su propia protección social» (Pan para el Mundo, 2020, p. 16). Añade que una vez de regreso en su país, en el contexto de sistemas muy débiles de 
seguridad social, la persona retornada puede hallarse en una situación de precariedad de apoyo social aún mayor que la que originalmente la condujo a emigrar.

Como señala el informe, los desafíos de la reintegración en los países del Norte y Oeste de África presentan particularidades, que escapan a la caracterización típica de la literatura sobre reintegración (Pan para el Mundo, 2020, p. 12). Ello debido a que en la región analizada en el informe se vive un contexto de emergencia, el cual impacta de manera muy significativa en la situación de quienes retornan a sus países de origen. Es así como las vuelve más vulnerables que a quienes retornan en otros contextos y tiene un efecto perjudicial que alcanza no solo a las personas retornadas sino también a sus familiares. Ello, ya sea porque se priva de manera imprevista a estos últimos de fuentes de ingresos vía remesas o debido a que los pone en la situación de tener que hacerse cargo económicamente de personas adicionales.

«El concepto de "reintegración" presupone -señala el informe- una integración previa en un sistema social, político y económico preexistente», añadiendo que esto es precisamente lo que se halla ausente en el caso de quienes son retornados desde Libia y Níger, ya que sus países de origen son estructuralmente débiles (Pan para el Mundo, 2020, p. 16). Esta es también una razón crucial para que muchas personas retornadas emprendan nuevamente, al cabo de poco tiempo, el intento de migrar.

Como bien observa el informe, el énfasis desproporcionado en políticas de retornos se lleva a cabo al precio de sacrificar o reducir significativamente otras opciones, tales como la existencia de rutas migratorias seguras y regulares o la contribución al Desarrollo Estructural de los Estados (Pan para el Mundo, 2020 p. 16). Esta última, en el mediano y largo plazo podría ser una fórmula mucho más efectiva de reducir la masividad de la movilidad humana.

Por último, es importante apuntar que las políticas de retornos se insertan en un cuadro más general, en el cual el componente de seguridad ocupa el lugar central de las políticas migratorias, con frecuencia con un serio impacto negativo en los derechos humanos de las personas en situación de movilidad. La práctica masiva de retornos de migrantes tiene evidentemente un objetivo disuasorio, en el sentido de enviar un mensaje al resto de la población de los países de origen de que encontrarán graves obstáculos para llegar a los Estados a los que pretenden migrar. No obstante, estas medidas difícilmente cumplen su propósito, fortaleciéndose, en cambio, rutas alternativas y más peligrosas para quienes buscan migrar. Por lo demás, de acuerdo con los estándares internacionales de derechos humanos, las medidas disuasivas no pueden desarrollarse legítimamente al costo de violar tales derechos.

\section{Bibliografía}

Attir, M. O. (2018) North African Regular and Irregular Migration: The Case of Libya. New England Journal of Public Policy, 30(2), pp. 1-4. Recuperado de https://scholarworks.umb.edu/nejpp/vol30/iss2/5/

Ferstman, C. (2020) Human Rights Due Diligence Policies Applied to Extraterritorial Cooperation to Prevent «Irregular» Migration: European Union and United Kingdom Support to Libya. German Law Journal, 21(3), pp. 459-486. Recuperado de https://www.cambridge.org/core/journals/german-law-journal/article/humanrights-due-diligence-policies-applied-to-extraterritorial-cooperation-to-preventirregular-migration-european-union-and-united-kingdom-support-tolibya/38D7DC3CE11420B2658CC8861FD14368 
Kirby, P. (2020) Sexual violence in the border zone: the EU, the Women, Peace and Security agenda and carceral humanitarianism in Libya. International Affairs, 96(5), pp. 1209-1226. Recuperado de https://doi.org/10.1093/ia/iiaa097

Kleist, N. (2017) Disrupted migration projects: the moral economy of involuntary return to Ghana from Libya. Africa: The Journal of the International African Institute, 87(2), pp. 322-342. Recuperado de https://muse.jhu.edu/article/656693

Mlambo, V. H. (2020) Externalization and Securitization as Policy Responses to African Migration to the European Union. African Human Mobility Review, 6(3), $\mathrm{pp}$ 94-109.

Recuperado

de https://sihma.org.za/journals/5.\%20Externalization\%20and\%20Securitization\%2 0as\%20Policy\%20Responses\%20AHMR\%203:2020.pdf

OIM (2018). Un marco para el retorno voluntario asistido y la reintegración. Recuperado de https://publications.iom.int/es/books/un-marco-para-el-retornovoluntario-asistido-y-la-reintegracion

ONU, Committee on the Protection of the Rights of all Migrants Workers and Members of their Families (2019). Concluding observations on the initial report of Libya (CMW/C/LBY/CO/1), 8 May. Recuperado de https://digitallibrary.un.org/record/3863940?ln=es

ONU, Consejo de Derechos Humanos (2019). Visita al Níger: Informe del Relator Especial sobre derechos humanos de los migrantes (A/HRC/41/38/Add.1), 16 de mayo. Recuperado de https://www.undocs.org/es/A/HRC/41/38/Add.1

ONU, Consejo de Derechos Humanos (2018). Informe del Relator Especial sobre derechos humanos de los migrantes (A/HRC/38/41), 4 de mayo. Recuperado de: https://www.undocs.org/es/A/HRC/38/41 